\title{
Why Aboutness Matters: Meta-Fictionalism as a Case Study
}

\author{
Matteo Plebani ${ }^{1}$ (D)
}

Received: 11 October 2019 / Revised: 3 September 2020 / Accepted: 10 September 2020 /

Published online: 6 October 2020

(C) The Author(s) 2020

\begin{abstract}
Recent work in the philosophy of language attempts to elucidate the elusive notion of aboutness (Berto 2018; Lewis 1988; Fine 2017a, b; Hawke 2017; Moltmann 2018; Yablo 2014). A natural question concerning such a project has to do with its motivation: why is the notion of aboutness important? Stephen Yablo (2014) offers an interesting answer: taking into consideration not only the conditions under which a sentence is true, but also what a sentence is about opens the door to a new style of criticism of certain philosophical analyses. We might criticize the analysis of a given notion not because it fails to assign the right truth conditions to a class of sentences, but because it characterizes those sentences as being about something they are not about. In this paper, I apply Yablo's suggestion to a case study. I consider meta-fictionalism, the view that the content of a mathematical claim $\mathrm{S}$ is 'according to standard mathematics, S'. I argue, following Woodward (2013), that, on certain assumptions, meta-fictionalism assigns the right truth-conditions to typical assertoric utterances of mathematical statements. However, I also argue that meta-fictionalism assigns the wrong aboutness conditions to typical assertoric utterances of mathematical statements.
\end{abstract}

Keywords Fictionalism $\cdot$ Aboutness $\cdot$ Stephen Yablo

\section{Introduction}

The notion of aboutness has recently attracted the attention of philosophers of language and logic (see Berto 2018; Lewis 1988; Fine 2017a, b; Hawke 2017;

Matteo Plebani

matteo.plebani@unito.it

1 Dipartimento di Filosofia e Scienze dell’Educazione, Università degli Studi di Torino, 10124 Turin, Italy 
Moltmann 2018; Yablo 2014). It is natural to wonder why these philosophers believe that characterizing the elusive notion of aboutness is an important project. Stephen Yablo has offered an interesting answer: focusing on what a sentence is about, i.e. on the subject matter of that sentence, rather than merely on its truth conditions, could open up the door to a new style of criticism of certain philosophical doctrines. In the words of Yablo:

How many times have you heard a philosopher reject the analysis of $P$ as $\varphi$ on the grounds that their truth-conditions differ; $P$ can be true when $\varphi$ is false, or vice versa? (Plato on justice, Gettier on knowledge, Frankfurt on freedom and responsibility,...) Broadening the focus from truth conditions gives us another way to challenge proposed philosophical analyses. $P$ and $\varphi$ may be true in the same cases, but $\varphi$ gets the subject matter wrong; $P$ is about one thing, $\varphi$ is about something else. How many times have you heard a philosopher argue like that? (Yablo 2014, pp. 15-6)

This paper tests Yablo's idea of criticizing a philosophical analysis not because it gets the truth-conditions of certain sentences wrong, but because it gets the subject matter of those sentences wrong.

Our case study will be meta-fictionalism about mathematical discourse, the view that the content of a mathematical claim $\mathrm{S}$ is 'according to standard mathematics, S'. Yablo (2001) presents an argument against meta-fictionalism based on considerations that meta-fictionalism does not account for the aboutness and the modal/epistemological status of mathematical claims. Woodward (2013) replies to Yablo's objection by offering an account of metafictionalism in which mathematical claims receive the right modal status. I will argue that, under certain conditions, this is an effective reply to the modal problems of meta-fictionalism (section 2). However, Woodward's reply leaves the aboutness problem raised by Yablo untouched (section 3). Properly appreciated, the aboutness considerations raised by Yablo provide a challenge to meta-fictionalism that Woodward's account does not answer.

\section{Yablo's Modal Objection to Meta-Fictionalism and Woodward's Reply}

According to mathematical fictionalism, mathematics works like fiction. When we utter a mathematical statement $\mathrm{S}$ in order to make a claim, we do it in a "fictional or makebelieve spirit" (Yablo 2001, p.74). We do not really assert the literal content of S: we quasi-assert that content in order to assert something else, which is the real content of our claim. Understood in this way, mathematical fictionalism is a version of "hermeneutic fictionalism" (see Burgess and Rosen 1997): it aims at representing the actual content of our mathematical claims, not at replacing them with assertions having a different content. This is important in order to evaluate the tenability of different fictionalist accounts.

Different versions of fictionalism disagree about what the real content of our mathematical assertions is. According to meta-fictionalism, the real content of a pure or applied mathematical claim $\mathrm{S}$ is 'according to standard mathematics, $\mathrm{S}$ '. Consider 
two mathematical claims, one from pure mathematics and the other from applied mathematics:

(P) $2+3=5$.

(A) The number of planets $=8$.

The real content of these statements, according to meta-fictionalism, is:

(MP) According to standard mathematics, $2+3=5$.

(MA) According to standard mathematics, the number of planets $=8$.

Yablo (2001) presents some reasons to be dissatisfied with this account. These are reasons to think that meta-fictionalism misrepresents the actual content of our mathematical claims. Woodward (2013, p. 6) does not consider this a problem: he explicitly says that he does not see meta-fictionalism as an account of the content of our mathematical claims. However, the context of Yablo's discussion of metafictionalism is precisely that in which meta-fictionalism is presented as a theory of the real content of our mathematical statements. Yablo is complaining that metafictionalism is inadequate as an account of the meaning of our mathematical claims. It does not seem a very effective reply to say it was never meant to be such an account. Therefore, I will stick with Yablo's view about the aims of meta-fictionalism.

One of Yablo's objections to meta-fictionalism has to do with the apparent mismatch between the modal status of pure mathematical claims and that of the content that metafictionalism assigns to them. The equation ' $2+3=5$ ' sounds like a necessary truth, whereas it seems to be a contingent matter that according to standard mathematics, $2+$ $3=5$. Standard mathematics could have been different, after all. (A similar worry about the epistemological status of mathematical claims is the following: $2+3=5$ is a priori knowable, whereas it is not a priori that standard mathematics is the way it is.) Moreover, if one tries to treat the expression 'standard mathematics' as a rigid designator referring to all the truths of pure and applied mathematics, 'according to standard mathematics, $2+3=5$ ' turns out to be necessary, but so does 'according to standard mathematics, the number of planets $=8$, which does not sound like a necessary truth (there could have been more or fewer planets).

Woodward (2013) argues that meta-fictionalists can reply to this objection by employing a certain account of the way the operator 'according to the fiction ...' works (p. 205):

\section{According to THE FICTION, $p$ iff $\square$ (EXPLICIT \& ENCYCLOPAEDIA $\rightarrow p$ ).}

We can 'think of the story's explicit content as the conjunction of the axioms that characterize the theory upon which the fictionalist's account is parasitic" (p. 204) and think of the ENCYCLOPAEDIA(w) as "the nominalistic truths that hold at w" (p. 206). 
An alternative way to interpret the fictionalist prefix is "via counterfactual conditionals" (p. 207):

According to the FICTION, p iff EXPLICIT $\square \rightarrow$ p. $^{1}$

On this reading, 'according to the FICTION, p' is true at a world $w$ if and only if (iff) the closest worlds to $\mathrm{w}$ where the axioms of the mathematical fiction are true are such that $\mathrm{p}$ is true at those worlds. This account of the "according to the fiction" operator yields the desired results: "EXPLICIT $\square \rightarrow 2$ $+3=5$ " is true at all worlds, given that, for any world $\mathrm{w}$, all the worlds closest to $\mathrm{w}$ where the mathematical axioms hold are such that $2+3=5$ is true at those worlds. "EXPLICIT $\square \rightarrow \#$ planets $=8$ ", on the other hand, despite being true at the actual world, is not true at all worlds. Consider a world $\mathrm{v}$ in which there are seven planets: the closest possible worlds to $\mathrm{v}$ in which the standard mathematical axioms are true are worlds where the number of planets is 7 , not 8. This means that "EXPLICIT $\square \rightarrow$;\#planets $=8$ " is not true at $\mathrm{v}$.

The appearance of a mismatch in modal status between mathematical claims $\mathrm{P}$ and A and their meta-fictionalist paraphrases MA and MP was illusory. MP turns out to be necessary and MA contingent, as desired. The identity of modal status between mathematical claims and their meta-fictionalist interpretations has been restored.

\section{Truth Conditions and Content}

We may generalize the result obtained in the previous section: the identity of modal status between $\mathrm{P}$ and MP, on the one side, and A and MA, on the other, can be seen as just a reflection of the identity of their truth-conditions. On some relatively mild assumptions, the truth conditions that Yablo assigns to the real content of A are the same as those that Woodward assigns to MA and the truth conditions that Yablo assigns to the real content of $\mathrm{P}$ are the same that Woodward assigns to MP.

On Yablo's account, what is asserted when somebody utters a mathematical statement is not the platonistic content of $\mathrm{S},|\mathrm{S}|$ (also known as the full, or literal, or compositional content of $\mathrm{S}$ ), but the concrete content of $\mathrm{S},\|\mathrm{S}\|$, defined in this way:

$\|\mathrm{S}\|$ is the proposition true in a world $\mathrm{w}$ iff $\mathrm{S}$ is true in some $\mathrm{v}$ concretely indiscernible from $\mathrm{w}$, albeit perhaps richer than $\mathrm{w}$ in mathematical objects (Yablo 2010, p. 3) ${ }^{2}$

\footnotetext{
${ }^{1}$ Following Woodward (2013), I present two interpretations of the fictionalist prefix. I think this is useful, because some philosophers might prefer the first interpretation and others the second one; if this were the case, it would be important to realize that for present purposes nothing substantial hinges upon choosing one interpretation over the other: both assign the right modal status to MA and MP. In any case, it is important to stress, as one referee pointed out, that the counterfactual analysis of the fictionalist prefix is not needed to assign the right modal status to "the number of planets $=8$ ". The contingency of "according to standard mathematics, the number of planets $=8$ " is accounted for also by the first interpretation of the fictionalist prefix, in virtue of Wooodward's account of ENCYCLOPAEDIA (w) (see Woodward 2013, p. 206).

${ }^{2}$ See Rosen (2001, p.75) for a similar idea.
} 
The equivalence with Woodward's proposal can be appreciated by reconsidering one way in which he interprets the fictionalist prefix, "via counterfactual conditionals" (Woodward 2013, p.8):

\section{According to the FICTION, p iff EXPLICIT $\square \rightarrow$ p.}

This means, as Woodward explains, that 'according to the FICTION, p' is true at w iff the closest worlds to $\mathrm{w}$ where the axioms of the mathematical fiction are true are such that $\mathrm{p}$ is true at those worlds. Yablo's definition of the real content of S is different from the counterfactual definition adopted by the meta-fictionalist. According to Yablo's definition, $\|\mathrm{S}\|$ is true at world $\mathrm{w}$ iff $|\mathrm{S}|$ is true at some world w' that is concretely indistinguishable from w. According to meta-fictionalism, on the other hand, $\|\mathrm{S}\|$ is true at $\mathrm{w}$ iff $|\mathrm{S}|$ is true at all the closest possible worlds to $\mathrm{w}$ in which standard mathematics is true. However, making a couple of relatively mild assumptions, we get the result that $\|\mathrm{S}\|$ is true at $\mathrm{w}$ according to Yablo iff $\|\mathrm{S}\|$ is true at $\mathrm{w}$ according to the meta-fictionalist.

The assumptions we need are (i) that the closest possible worlds to w where standard mathematics is true are concretely indiscernible from w; (ii) that if $\mathrm{w}$ and w' are concretely indistinguishable and both contain abstract mathematical objects, then $|\mathrm{S}|$ is true in w iff $|\mathrm{S}|$ is true in w'.

The motivation for (i) is that for every world w, there is a world w' that is a "platonistic duplicate" of w: a world that is concretely indiscernible form w but also contains abstract mathematical objects (if $\mathrm{w}$ contains numbers, then $\mathrm{w}$ is its own platonistic duplicate). Given that w' resembles w to a higher degree than a world w" that is different from $\mathrm{w}$ in some concrete respects, w' is closer to w than w". This means that the closest possible worlds to $\mathrm{w}$ in which standard mathematics is true are platonistic duplicates of $\mathrm{w}$. This means that if $\|\mathrm{S}\|$ is true according to the metafictionalist definition, it true according to Yablo's definition.

Why is it always possible to find a platonistic duplicate of w? Because it is natural to assume that the existence of abstract mathematical objects is compatible with every way the world might be in concrete respects. To illustrate: no matter how many planets there are in $\mathrm{w}$, there must be a platonistic world with as many planets as w. ${ }^{3}, 4$

The motivation for (ii) can be illustrated with an example. Let S be: "The number of planets is eight". Suppose that w and w' both contain numbers and suppose that there are as many planets in w as in w': then either $|\mathrm{S}|$ is true at both worlds or $|\mathrm{S}|$ is false at both worlds. More generally, the only two relevant factors for the truth of an applied mathematical sentence $S$ are the presence of abstract mathematical objects and the way the world is in concrete respects. (Pure mathematical sentences are true in all the worlds containing abstract mathematical objects and false or without a truth-value in all the rest). Given (i) and (ii) we can show that if $\|S\|$ is true at $w$ according to Yablo's definition, then $\|S\|$ is true at $\mathrm{w}$ according to the meta-fictionalist. Suppose $\|\mathrm{S}\|$ is true at $\mathrm{w}$ according to Yablo's

\footnotetext{
${ }^{3}$ A platonistic world is a world where abstract mathematical objects exist and have their standard properties, i.e. a world where standard mathematics is true.

${ }^{4}$ See Hellman (1989) on the non-interference provisio. Yablo (2012) defends the idea that the question of how the world is concretely is orthogonal to the question whether there are abstract mathematical objects. See also Horgan (1984) and Yablo (2017).
} 
definition: this means that there is a platonistic world w' that is concretely indistinguishable from $\mathrm{w}$ and $|\mathrm{S}|$ is true at $\mathrm{w}$ '. Assuming (i), one of the closest worlds to $\mathrm{w}$ where the axioms of mathematics are true, call it $\mathrm{w}^{*}$, is concretely indistinguishable from $\mathrm{w}$. So $\mathrm{w}$ ' is concretely indiscernible from $\mathrm{w}$, which is concretely indiscernible from $\mathrm{w}^{*}$. Concrete indiscernibility is an equivalence relation, hence it is transitive, which means that $\mathrm{w}^{\prime}$ and $\mathrm{w}^{*}$ are concretely indiscernible. $|\mathrm{S}|$ is true at $\mathrm{w}^{\prime}, \mathrm{w}^{\prime}$ is concretely indiscernible from $\mathrm{w}^{*}$, and both worlds are platonistic worlds. Combined with (ii), this yields the result that $\|\mathrm{S}\|$ is true at $\mathrm{w} . \mathrm{W}^{*}$ was chosen arbitrarily among the platonistic worlds that are closest to $\mathrm{w}$, which means that assuming that $\|\mathrm{S}\|$ is true at $\mathrm{w}$ according to Yablo's definition, $\|\mathrm{S}\|$ is true at $\mathrm{w}$ according to the meta-fictionalist definition.

One way to justify (i) and (ii) at once is to hold that for every world w, there is exactly one world w' that is the "concrete duplicate" of w: a world concretely indistinguishable from $\mathrm{w}$, but different from w. In other words: if w and w' are concretely indiscernible, then the only difference between $\mathrm{w}$ and $\mathrm{w}$ ' is the presence or absence of abstract objects. If this were the case, then both the meta-fictionalist and Yablo's definition of $\|\mathrm{S}\|$ would be equivalent to: $\|\mathrm{S}\|$ is true at w iff $|\mathrm{S}|$ is true at w or $|\mathrm{S}|$ is true at the concrete duplicate of $\mathrm{w}$.

My goal is not to defend (i) and (ii). Some philosophers might find them plausible and others not, but this hardly matters here. Woodward (2013, pp. 205-7) offers an alternative meta-fictionalist analysis of the real content of $\mathrm{S}$ : the real content of $\mathrm{S}$ is true at $\mathrm{w}$ iff $\mathrm{S}$ is true at all the platonistic worlds that are concretely indiscernible from $\mathrm{w}$. Yablo (2014, p. 34) offers virtually the same analysis. Moreover, Yablo and Woodward agree that the right truth conditions for sentences like "The number of planets is eight" are that there be eight planets. ${ }^{5}$

What I want to do is to argue that even granting that Yablo and the meta-fictionalist assign the same truth-conditions to sentences like "The number of planets is eight", there is still room for Yablo to complain about the meta-fictionalist definition of the real content of such sentences.

What could be wrong with the meta-fictionalist account of the content of our mathematical claims, if such an account assigns the right truth conditions to a typical assertoric utterance of a mathematical sentence $S$ ? The crucial point is that being true at the same worlds only guarantees identity of truth conditions. And there seem to be cases where two claims can differ in content while having the same truth conditions. Consider the following pairs of statements:

1. $2+3=5$ vs $\varepsilon^{l \pi}+1=0$.

2. Snow is white vs "snow is white" is true.

3. \#Planets $=8$ and $2+2=4$ vs \#Planets $=8$.

4. $\{$ Socrates $\} \subseteq\{\mathrm{x}: \mathrm{x}$ is a man $\}$ vs Socrates is a man.

\footnotetext{
${ }^{5}$ Both Woodward and Yablo's definitions of the real content of a mathematical sentence presuppose that the existence of abstract mathematical object is contingent: there are worlds in which abstract mathematical objects exist (platonistic worlds) and worlds where they do not exist (nominalistic worlds). For a defense of the view that the existence of abstract mathematical object is contingent (in some sense) see Yablo (2012, p. 1013) and references therein. Given that I am interested in the debate between Yablo and Woodward and the contingency of abstract mathematical objects' existence is an assumption they share, I will not discuss the tenability of this assumption here.
} 
On standard assumptions, the statements on the right hand side have the same truth conditions as those on the left hand side. However, the statements on the right hand side seem to have a different content from those on the left hand side. So there is at least some reason to suspect that more is needed for the identity of content than the identity of truth conditions. ${ }^{6}$

\section{Aboutness as a Further Constraint}

An interesting working hypothesis is that what is missing in a truth-conditional analysis of meaning is a proper appreciation of the role played by the aboutness of a certain statement.

The statement " $2+3=5$ " differs from " $\varepsilon^{l \pi}+1=0$ ", according to this hypothesis, by virtue of a difference in subject matter: the former is (just) about the natural numbers, where the latter is about real numbers as well. Similarly, "snow is white" is not about sentences at all, as "Socrates is a man" is not about sets at all, despite the fact that they are truth-conditionally equivalent to claims about sentences and sets.

Of course, to make our working hypothesis more precise, we need a theory of aboutness. Yablo (2014) presents precisely such a theory, but I will not go into the details here. What suffices for present purposes is to note that we can criticize some accounts of the meaning of certain claims on the ground of misrepresenting what those claims are about.

\section{A New (Old) Challenge to Meta-Fictionalism}

Meta-fictionalism in mathematics, understood in a hermeneutic spirit, is an account of the content of our mathematical claims (pure and applied). The identification between truth conditions and content is doubtful. This means that meta-fictionalism should do more than assign the right truth conditions to mathematical claims like $\mathrm{P}$ and $\mathrm{A}$. It should represent them as being about the right subject matter as well. It is here that problems arise.

$\mathrm{P}$ and $\mathrm{A}$ do not seem to be about fictions at all. Nor do they look as counterfactual claims. 'The number of planets $=8$ ', in particular, seems to be a straightforward claim about the actual world. Now, it is true that:

$$
\begin{aligned}
& \text { (FA) } \exists 8 \mathrm{X} \text { ( } \mathrm{X} \text { is a planet), } \\
& \text { and }
\end{aligned}
$$$$
\left(\mathrm{FA}^{*}\right) \text { EXPLICIT } \square \rightarrow \text { \#Planets }=8
$$

are true at the same worlds, but the content of the claim that the number of planets is eight is best represented by FA because it better reflects the intuitive subject matter of such a claim. Somebody uttering A could be unaware of the existence of something like

\footnotetext{
$\overline{{ }^{6}}$ This problem is well known: see Barwise (1997) for an early discussion and Duží and Jespersen (2015) for a recent one.
} 
'standard mathematics', or in any case, upon reflection, she could note that facts about standard mathematics are not what she is talking about when she utters those statements. Issues of aboutness are related to issues of concern. It would be desirable not to represent people claiming that $\mathrm{A}$ as concerned about the content of standard mathematics. Yablo himself mentions this problem in his 2001 paper. The mismatch in modal status is just one of the problems for meta-fictionalism that Yablo points towards. Here is how he goes on:

....there are problems of concern, of what we care about. It is a matter of concern that the number of starving people is large and rising. We do not seem to care in the same way about the content of standard math. If the metafictionalist is correct, though, quasi-asserting that the number of starving people is large is really asserting that the number is large according to standard math. And it does not seem plausible that what we regret or deplore or are concerned about here is that the number is large according to standard math. Because that would be to deplore inter alia part of the content of standard math.

Third is a phenomenological worry. When we say that the number of starving people is very large, we do not feel ourselves to be talking (even a bit!) about the content of a mathematical story. Our subject matter is people and our thought is that a lot are starving. "The number of apostles is twelve" is no more about a story than "snow is white" concerns the rules of English. (Yablo 2001, p. 76)

The last point Yablo mentions can serve as an illustration. Imagine somebody advocating a theory according to which the content of the claim that snow is white is the following:

(Msnow) "snow is white" is true.

Suppose that Cook (2012) is right: (Msnow) is necessarily equivalent to the claim that snow is white: they are true at the same worlds. They still do not express the same content. "Snow is white" is not about (English) sentences at all. It is useful, in order to understand Yablo's critique of meta-fictionalism, to look at figuralism, Yablo's favorite version of fictionalism. According to figuralism, the way in which the mathematical fiction works is as an expressive aid: by indulging in the mathematical pretense, we are able to express some contents that otherwise would be very difficult to put into words. The fiction, however, is a 'medium' to convey these contents, not the subject matter of our claims. The role of mathematical fiction is analogous to that of the rules of English. ${ }^{7}$ And meta-fictionalism should be rejected for the same reasons why we would reject a theory of the content of ordinary statements which identifies them with something like (Msnow).

\footnotetext{
7 "I am certainly relying on the rules of English when I utter the words "snow is white." It is those rules that make my utterance a way of saying that snow is white. It is just that relying on rules is one thing; talking about those rules is another" (Yablo 2001, p. 76).
} 


\section{Conclusions}

Yablo has recently complained that focusing only on truth conditions could preclude new ways to assess the tenability of some philosophical analyses.

The debate about meta-fictionalism could be a case study for this new approach. Yablo's argument against meta-fictionalism is based on the consideration that metafictionalism seems not to account for the aboutness and the modal/epistemological status of mathematical claims. Woodward has offered us reasons to think that the metafictionalist can resist one of these charges: meta-fictionalists can account for the modal status of mathematical claims. However, there is still room for an 'objection from aboutness' against meta-fictionalism. Yablo himself stresses the importance of considering the intuitive aboutness of pure and applied mathematical claims, and I have been arguing that these considerations give us ground for an interesting challenge to metafictionalism.

I did not discuss Yablo's idea that meta-fictionalism assigns the wrong epistemological status to sentences like " $2+2=4$ ". The meta-fictionalist paraphrase of such a sentence is "According to standard mathematics, $2+2=4$ ". That two plus two is four should be knowable a-priori, Yablo argues, but we need to know what the axioms of standard mathematics are in order to know that according to standard mathematics $2+$ $2=4$, and we can know the content of standard mathematics only a-posteriori. On Woodward's account, knowing that according to standard mathematics, $2+2=4$, essentially means knowing that the axioms of standard mathematics entail that $2+$ $2=4$, because the expression "standard mathematics" has the same reference in every world: a mathematical theory that includes the standard axioms. Let us grant that one can use "standard mathematics" in this way. A remark by Field (1984, p. 512) is relevant here. To know that "standard mathematics" refers to a list of axioms that includes the principle of mathematical induction, one has to learn something that seems empirical in nature: that the mathematical community accepts the principle of mathematical induction. Confronted with a list of axioms, somebody might be able to realize that those axioms entail a certain conclusion, without realizing that the standard axioms entail that conclusion, if she does not know what the standard axioms are. This is compatible with the idea that "the standard axioms" refers to the same set of axioms in every world.

Perhaps the problem of the epistemological status of the meta-fictionalist paraphrases of sentences like " $2+2=4$ " is connected with our previous discussion. An account of content focused merely on truth conditions might miss some important aspects of the meaning of a sentence. There might be pairs of sentences $\mathrm{S}$ and $\mathrm{S}^{\prime}$ such that $S$ and $S^{\prime}$ are true under the same circumstances and yet $S^{\prime}$ is harder to know than $S$ (Yablo 2014, Chapter 7). An example of such a pair of sentences might be "the following list of axioms entails that $2+2=4$ " on the one hand and "the standard mathematical axioms entail that $2+2=4$ " on the other.

The connection between the subject matter of a sentence and the conditions under which a subject is able to know that such a sentence is true is an important point, but one that I prefer to set aside for the moment. The goal of the paper was to discuss an example of a philosophical analysis that assigns the right truth conditions to a class of sentences, but characterizes those sentences as being about something they are not about. Meta-fictionalism is an interesting example of such an analysis. 
Funding Open access funding provided by Università degli Studi di Torino within the CRUI-CARE Agreement. The research activity that led to the realization of this paper was carried out within the Department of Excellence Project of the Department of Philosophy and Educational Sciences of the University of Turin (ex L. 232/2016). The author also acknowledges financial support from FEDER/Ministerio de Ciencia, Innovación y Universidades - Agencia Estatal de Investigación - Proyecto (FFI2017-82534-P).

Open Access This article is licensed under a Creative Commons Attribution 4.0 International License, which permits use, sharing, adaptation, distribution and reproduction in any medium or format, as long as you give appropriate credit to the original author(s) and the source, provide a link to the Creative Commons licence, and indicate if changes were made. The images or other third party material in this article are included in the article's Creative Commons licence, unless indicated otherwise in a credit line to the material. If material is not included in the article's Creative Commons licence and your intended use is not permitted by statutory regulation or exceeds the permitted use, you will need to obtain permission directly from the copyright holder. To view a copy of this licence, visit http://creativecommons.org/licenses/by/4.0/.

\section{References}

Barwise, J. (1997). Information and impossibilities. Notre Dame Journal of Formal Logic, 38, 488-515.

Berto, F. (2018). Aboutness in imagination. Philosophical Studies, 175(8), 1871-1886.

Burgess, J. P., \& Rosen, G. (1997). A subject with no object: Strategies for Nominalistic interpretation of mathematics. Oxford: Oxford University Press.

Cook, R. T. (2012). The T-schema is not a logical truth. Analysis, 72(2), 231-239.

Duží, M., \& Jespersen, B. (2015). Introduction. Synthese, 192(3), 525-534.

Field, H. (1984). Is mathematical knowledge just logical knowledge? The Philosophical Review, 93(4), 509552. https://doi.org/10.2307/2184826.

Fine, K. (2017a). A theory of Truthmaker content I: Conjunction, disjunction and negation. Journal of Philosophical Logic, 46(6), 625-674.

Fine, K. (2017b). A theory of Truthmaker content II: Subject-matter, common content, remainder and ground. Journal of Philosophical Logic, 46(6), 675-702.

Hawke, P. (2017). Theories of Aboutness. Australasian Journal of Philosophy, 96(4), 697-723.

Hellman, G. (1989). Mathematics without numbers: Towards a modal-structural interpretation. Oxford: Oxford University Press.

Horgan, T. (1984). Science nominalized. Philosophy of Science, 51(4), 529-549.

Lewis, D. K. (1988). Relevant implication. Theoria, 54(3), 161-174.

Moltmann, F. (2018). An object-based truthmaker semantics for modals. Philosophical Issues, 28(1), 255288.

Rosen, G. (2001). Nominalism, Naturalism, Epistemic Relativism. Nô̂s, 35(s15), 69-91.

Woodward, R. (2013). A Yablovian dilemma. Thought: A Journal of Philosophy, 1(3), 200-209.

Yablo, S. (2001). Go figure: A path through fictionalism. Midwest Studies in Philosophy, 25(1), 72-102.

Yablo, S. (2010). Things: Papers on objects, events, and properties. Oxford: Oxford University Press.

Yablo, S. (2012). Explanation, extrapolation, and existence. Mind, 121(484), 1007-1029.

Yablo, S. (2014). Aboutness. Princeton: Princeton University Press.

Yablo, S. (2017). If-Thenism. Australasian Philosophical Review, 1(2), 115-132.

Publisher's Note Springer Nature remains neutral with regard to jurisdictional claims in published maps and institutional affiliations. 